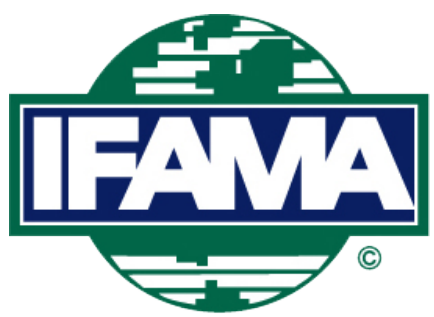

International Food and Agribusiness Management Review

Volume 22 Issue 5, 2019; DOI: 10.22434/IFAMR2019.0008

Received: 15 January 2019 / Accepted: 22 May 2019

\title{
What strategies do dairy companies realize? Using content analysis to examine strategies in the German dairy market \\ RESEARCH ARTICLE
}

\author{
Julia Höhler ${ }^{\oplus a}$ and Rainer Kühl ${ }^{b}$ \\ ${ }^{a}$ Postdoc, ${ }^{b}$ Professor, Justus Liebig University Giessen, Institute of Farm and \\ Agribusiness Management, Senckenbergstr. 3, 35390 Giessen, Germany
}

\begin{abstract}
A realized strategy can be understood as the sum of a company's observable strategic actions over time. This concept of strategy is difficult to grasp empirically. However, the content analysis enables a systematic, dynamic and theoretically sound recording of realized strategies. To demonstrate the potential of the method in capturing strategies we encode 4,158 pieces of information about strategic actions of ten European dairy companies in the German market for over 11 years. Based on this we suggest a mixed methods approach to learn more about the individual companies' competitive moves and their realized strategies. The companies investigated differ in their adaptation to changing environmental conditions and in particular in their brand policy. The trend 'animal welfare' shows that most dairy companies reacted late and left the initiative to the retail trade. Our approach can be applied to many questions in strategy research and promises new insights into the strategies of companies in the food industry.
\end{abstract}

Keywords: strategic management, content analysis, realized strategy, mixed methods, dairy JEL code: D22, L22, L66

(ํ) Corresponding author: julia.hoehler@agr.jlug.de 


\section{Introduction}

Strategies are indispensable for answering a relevant number of economic questions (Hambrick, 1980). It is therefore not surprising that a variety of methods are available for their empirical assessment. The advantages and disadvantages, the uses of different empirical methods in strategy research as well as their combination possibilities were first discussed fundamentally in a paper by Snow and Hambrick (1980). Since then, the empirical accessibility of strategies and corresponding empirical methods have rarely been discussed. Hafsi and Howard (2005) see a need for methods that capture the complexity and dynamics of reality. Durand et al. (2017) describe the lack of an integrated and empirically validated knowledge base in strategic management research. In their opinion theory and construct design often do not fit together in empirical studies.

Although a superior strategy is important for firms and although much research has been done about it, there is no consensus in literature about what strategy actually is (Markides, 2004; Ronda-Pupo and GuerrasMartin, 2012). Without presenting the entire discussion about the concept of strategy in the past decades, we will take up some classical concepts that are relevant to our contribution. Mintzberg (1978) sees one possibility of interpretation in understanding strategy as a pattern in a stream of decisions. He distinguishes between intended, deliberate, emergent, unrealized and realized strategies. Intended strategies cannot always be realized. Realized strategies are the result of deliberate strategies and emergent strategies. For Porter (1980) competitive strategies are formulated in the context of a company's strengths and weaknesses, industry opportunities and threats, broader societal expectations as well as personal values of the key implementers. Chandler (1962) describes the strategy of a company as 'the determination of the basic long-term goals and the objectives of an enterprise, and the adoption of courses of action and the allocation of resources necessary for carrying out these goals.' In contrast, Idenburg (1993) states that companies must react flexibly due to the unforeseen environment. As a consequence it is not possible to formulate explicit goals and develop a future perspective. From the point of view of the resource-based view (Barney, 1991) long-term competitive advantages can be achieved by building up resources and exploiting existing resources. All of the mentioned definitions have in common that a strategy results in a number of relevant actions or key areas for ensuring business success, such as price policy, innovations, product policy, co-operation, acquisitions or governance structures (see also Camerer, 1991).

The discovery of strategies as a pattern requires the observation of actions over a longer period of time. In order to compare companies and identify developments, actions must be divided into different strategic areas. Smith et al. (1991) define action as 'a specific and detectable competitive move, such as a price cut or a new product introduction, initiated by a firm to defend or improve its relative competitive position'. Surveys are the most commonly used method for capturing strategies (Voigt, 2011). However, they are characterized by systematic distortions of managers' responses and a focus on the intended strategy. Content analysis uses objective indicators to examine news and documents in a systematic and replicable manner. One advantage compared to surveys is that the method is not susceptible to response distortions. Furthermore, a high number of cases can be recorded independently of time and continuously. However, the disadvantage is that coding can cause distortions between different coders and within the codes of an individual coder. Overall, content analysis seems to be a particularly suitable method for the systematic and dynamic assessment of realized strategies.

The idea of using content analysis to capture strategies is not new. An area in which content analysis is already frequently used is competitive dynamics research. The goal is to investigate the actions and reactions of competitors (e.g. Ferrier et al., 1999; Smith et al., 2001; Short et al., 2018; Uhlenbruck et al., 2017). However, only those actions are sampled that provoke answers. It is questionable whether there is always an answer to a strategic action. Perhaps even those actions bring benefits that are not answered by the competitor. As a result, important actions could be overlooked. Chen et al. (1992) and Smith et al. (2001) distinguish between strategic and tactical actions. Further subdivisions regarding the nature of the action are not made by them, although they would be necessary to analyze strategies. Ferrier et al. (1999) use more detailed actions, but here, for example, merger and acquisitions are missing as important actions. Duriau 
et al. (2007) show that annual reports were often used as a data basis for content analyses in organization studies (see also Short and Palmer, 2008). Vracheva et al. (2016) analyze letters to stakeholders to determine the enterprise strategy. However, both formats can be strongly influenced by the company and they are not always accessible. Newspaper articles are another possible source, which could bypass some of the disadvantages of annual reports or letters. We would like to address a new field of application for content analysis in strategy research and show how trade journal articles can be used to draw conclusions about strategies. For our analysis we use a broad concept of strategy, which understands a realized strategy as the sum of observable strategic actions of the company. Our contribution is twofold. First, we demonstrate the so far untapped potential of content analysis in capturing strategies. We want to complement and refine the existing application of content analysis in order to analyze strategies. For this purpose, we systematically collect trade journal articles and code them according to a previously developed scheme. Our method is based on theoretical considerations and it is replicable. Second, we apply our method to the dairy industry. For a number of reasons and stakeholders, this market is an interesting object of investigation.

1. Consumers

The market is largely saturated and consumer spending on food is particularly low on the EU average (Eurostat, 2018). As a result, product diversification becomes increasingly relevant (Sexton, 2012). Consumers are willing to pay more money for certain process and product characteristics. Important trends include animal welfare, protein products, sustainability, GMO-free products, and sugar reduction. The growing premium segment includes pasture, hay and alpine milk (Mehlhose et al., 2019). It is a challenge for dairies to recognize new consumer trends in good time.

2. Food retailers

The concentration in food retailing continues to increase, allowing large retailers to use their structural advantages in negotiations with dairy companies (German Federal Cartel Office, 2014). In addition, food retailers have their own brands to compete with dairies. Their market shares are growing and they are increasingly innovating in the premium segment, which puts pressure on brand manufacturers (Mehlhose et al., 2019).

3. Dairy industry

The German dairy industry is the largest milk industry within the European Union (Eurostat, 2017). Market concentration has increased in recent years also as a result of increasing competition with European dairies. In 2016 the ten largest operators accounted for $44 \%$ of the supply (German Federal Ministry of Food and Agriculture, 2019). Turnover in 2017 amounted to 27.15 billion euros. The Association of the German Dairy Industry (2018) listed 153 companies and production sites. Cooperatives are the predominant form of organization. Their market share in terms of volume is about $70 \%$, while they generate $60 \%$ of sales revenues (German Federal Cartel Office, 2009). In contrast to private dairies, cooperatives are usually obliged to purchase all the milk of their members. Together with the long notice periods, this practice has been criticized by the competition authorities as an obstacle to competition (German Federal Cartel Office, 2012). Since higher margins can usually only be achieved through value-added concepts, the complexity of production and logistics increases. Due to the largely saturated market, some dairies concentrate on exports. On the international market for milk and milk products they compete primarily with dairies from New Zealand and the USA. In addition, they are subject to import restrictions (e.g. Russia) or customs duties (e.g. Mexico) (Mehlhose et al., 2019).

4. Agriculture

The number of dairy farmers has been falling continuously for years while the average herd size is increasing. Farmers rarely change their dairy, which is also due to the contractual conditions and has been investigated by the German Federal Cartel Office (2012) in recent years. Since the end of the quota in 2015 the milk volume is no longer fixed throughout the EU. The period shortly before and after the end of the quota was characterized by excess supply and low producer prices. Thereafter, 
prices have stabilized at a slightly higher level, but continue to fluctuate (Mehlhose et al., 2019). The dairies have to deal with volatile markets.

So far, there have been few empirical studies on dairy companies' strategies (Graubner et al., 2011; Höhler and Kühl, 2014; Valeeva et al., 2006; Van der Krogt et al., 2007). Strategies are usually only examined in specific areas, such as food safety and prices, rather than for companies as a whole. In addition, the results of some of the studies are difficult to reproduce as many different sources were searched. This goes hand in hand with the results of Bergh et al. (2017), who discuss the lack of reproducibility of study results in strategic management. What is missing is an approach that makes it possible to examine all the realized strategic actions of companies in a reproducible way. This is not only true for the dairy industry. Knowing the strategies enables researchers, for example, to draw conclusions about the adjustment behavior of companies and reactions to policy changes.

First, we explain our methodological approach and in particular the formation of the categories, the collection of the data as well as the coding. Subsequently, we present various evaluation options for the results of the content analysis. In the discussion we address the possible use of our results and limitations of the method.

\section{Content analysis of strategies in the dairy industry}

Content analysis is a method that allows making 'replicable and valid inferences from texts [...] to the contexts of their use' (Krippendorf, 2004). There are various forms of content analysis that differ in their objectives and in the depth with which the text is examined (Hijmans, 1996; Kohlbacher, 2006). Different methods are available for this purpose, such as Evaluative Assertion Analysis (Osgood et al., 1956), cognitive maps (Axelrod, 1976), relational content analysis (Roberts, 1997), semantic network analysis (Van Atteveldt, 2008) or the core sentence approach (Helbling and Tresch, 2011). Our goal is to identify patterns in the use of strategic actions. For this purpose, we do not analyze the sentences in depth.

\subsection{Category formation}

The application of the content analysis requires building categories (Berelson, 1952). Our categories are formed by the strategic actions of the actors (for details see supplementary Table S2 and S3). The actions are based on the resource-based view (Barney, 1991; Wernerfelt, 1984), on Porter's (1980) competitive strategies as well as on Ansoff's (1957) product market concept. As a result, strategic actions include all actions that can be used to develop and exploit resources, to achieve cost leadership or differentiation, to penetrate existing markets, enter new markets, develop new products and to create long-term competitive advantages. This results in the following categories:

- cooperation;

- participation;

- merger;

- acquisition;

- production capacity;

- location closure;

- market entry;

- investment;

- price policy;

- product policy;

- brand policy;

- advertising;

- product innovation;

- organizational design.

A resource is an asset which can lead to high profits. According to the resource-based view (Barney, 1991; Wernerfelt, 1984) resources should be developed and exploited in order to gain competitive advantages. A 
number of strategic actions are suitable for this purpose. Cooperation, participation, mergers and acquisitions, the development of production capacity and further investments are useful to develop and purchase resources. In order to use existing resources, product policy, brand policy, price policy, product innovations, and advertising can be employed. In addition, the reduction of resources may also be necessary, for example, by closing locations.

According to Porter (1980) competitive advantages can be achieved either through cost leadership or differentiation. These two orientations are reflected in particular in price policy, product policy, product innovation, brand policy, advertising, and the development of production capacity.

Ansoff (1957) distinguishes four strategies in his product market matrix. Thereby he differentiates between new and present markets and products. In market penetration, the present market and the present product are used to increase market shares. This can be achieved through more production capacity, price policy, advertising or the merger and acquisition of competitors. In the case of a market development new markets are entered with existing products. To this end a company can cooperate with other companies, use mergers and acquisitions, participate in other companies or enter a new market itself. In product development, the company remains in the existing market but develops new products. This works through product policy, investment in research and development or cooperation with other companies. Finally, there is the possibility of diversification, for which measures from the other strategies can be combined to open up new markets with new products.

Based on Ansoff's (1957) matrix, we further differentiate between domestic and foreign in the actions of cooperation, participation, merger, acquisition, production capacity and location closure. Domestic describes the location of the parent company and forms the existing market. Market entry is recorded for foreign markets. The other actions relate primarily to the strategy in the retail market: prices, product policy, branding, advertising and innovation. With the additional category organizational design, changes in the form of organization are recorded that may be necessary both for the exploitation of resources and for different market strategies.

\subsection{Data collection}

In our analysis we were interested in the top 10 European dairy companies in terms of turnover 2016 in the German market (Association of the German Dairy Industry, 2017, see Supplementary Table S1). We choose this sample because we assume that due to the size of the companies all relevant actions are reported in the media. Investigations of the remaining 142 smaller companies could be biased as not every action could be reported. In addition, sales figures for 2016 are available for these ten companies, which is not always the case for smaller companies. The companies cover $65 \%$ of the turnover in the German market (Association of the German Dairy Industry, 2018). They include both companies that were originally active in Germany as well as European companies from abroad (see Supplementary Table S1).

Our dataset consists of articles $(n=2,258)$ from the leading trade journal of the consumer goods industry in Germany (Lebensmittel Zeitung, 2017). With 130,000 unique users per month, this newspaper is not only relevant to the food industry itself but also for the downstream food retailers. The newspaper covers international, national and also regional developments. The target group consists of decision-makers in the trade and consumer goods industry as well as industry-related service providers. The newspaper articles have several advantages over financial statements. Unlike the former, the latter is not available for every company in our dataset as not all companies have to publish them in Germany. Some companies are also part of corporate groups (Theo Müller) or are active abroad (Arla from Sweden/Denmark) so that a comparison would be difficult even if financial statements were available. Furthermore, the information in the documents could be distorted by a company's balance sheet policy. What unites all companies is that they process milk in Germany and sell dairy products on the German market or on foreign markets. Even if the companies differ in their products and regional focus, they still compete in raw milk. Their activities and strategic actions are 
addressed in the journal. The articles were retrieved via an online database. The dataset covers 11 years; it ranges from 2007 to 2017. The keyword for the search was 'dairy' because we wanted to generate the widest possible dataset. A link to operators and the use of additional search terms (such as milk, butter, or cheese) could be used to further narrow down the data set or to find additional articles.

\subsection{Coding}

First, all company names were coded and the articles were assigned to the years. Our categories are formed by the identified strategic actions (for details, see Supplementary Table S2 and S3). Sentences and paragraphs that describe these strategic actions were our analytical units for coding the texts (Berelson, 1952; Weber, 1990).

Subsidiaries and their actions were allocated to the respective parent company insofar as the affiliation was specified. If a company in the top 10 emerged during the last 11 years through a merger the respective participants in the merger were individually coded and then assigned to the resulting company. This approach simplifies the comparison of companies.

The coding was carried out in MaxQDA, software for qualitative and mixed method research (MaxQDA, 2017). The use of the software allows handling of large amounts of data as well as the further processing of the codes in statistical software. Relevant sentences or paragraphs were manually coded according to the above categories. The coding of an analytical unit with several codes was possible. Moreover, the same action could be encoded several times if it was addressed in several paragraphs and articles. In doing so we implicitly considered the importance of various actions in reporting. However, a one-time consideration of actions mentioned in several cases is possible in principle. We coded manually in order to take longer sentences and meaning into account. In addition, this procedure makes it possible to divide the actions into domestic and foreign actions.

In total we identified 4,158 mentions of strategic actions. These were further processed in the analysis.

\section{Analysis of strategies in the dairy industry}

In the following, we propose different methods for the analysis of the data collected with the content analysis. We move from a general representation of all actions over the years to a representation for individual years and for individual companies. In addition, we form strategic groups and show how further findings can be gained by means of a panel data analysis. This mixed methods approach shows the range of potential uses of our data and allows different statements about the chosen strategies. First, we look at the dataset as a whole and the percentage distribution of the identified strategic actions (Figure 1, for more details see Supplementary Table S4).

\subsection{Descriptive statistics: strategies of all companies}

The high number of product policy measures (17.9\%) and product innovation (6.2\%) is in line with the high flop rate in the industry (Dijksterhuis, 2016). At the same time, brand policy measures $(12.8 \%)$ are often implemented. The market entries $(7.9 \%)$ into foreign markets could be interpreted as a result of market liberalization and saturated domestic markets. This figure provides a general overview.

In addition to consideration over the entire period, the actions used can also be analyzed for the individual years. This allows initial statements about the adaptation of companies to changing market conditions. The end of the milk quota represents an external shock and a new environment for the companies. The quantities of milk are no longer limited and allow an expansion of production capacities and thus the entry into new markets. However, if all dairies do so there is a risk of overproduction and price erosion. When looking at the evolution of the recorded actions over the years (Figure 2) it turns out that no more strategic actions were taken after the quota end. On the contrary, in 2016 even fewer actions ( 314 in total) were performed than in previous years. 

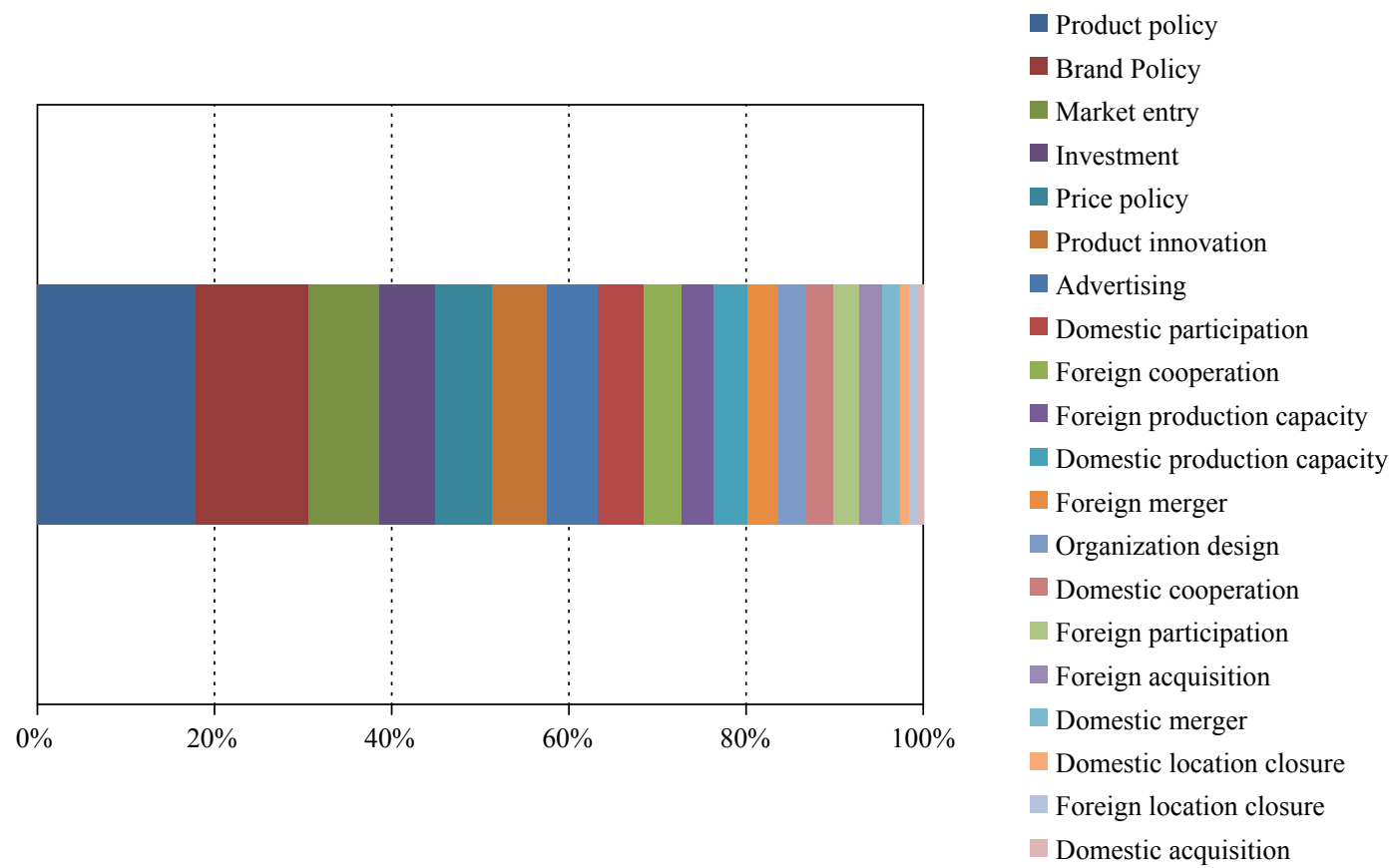

Figure 1. Percentage distribution of strategic actions of the top 10 dairy companies, 2007-2017.

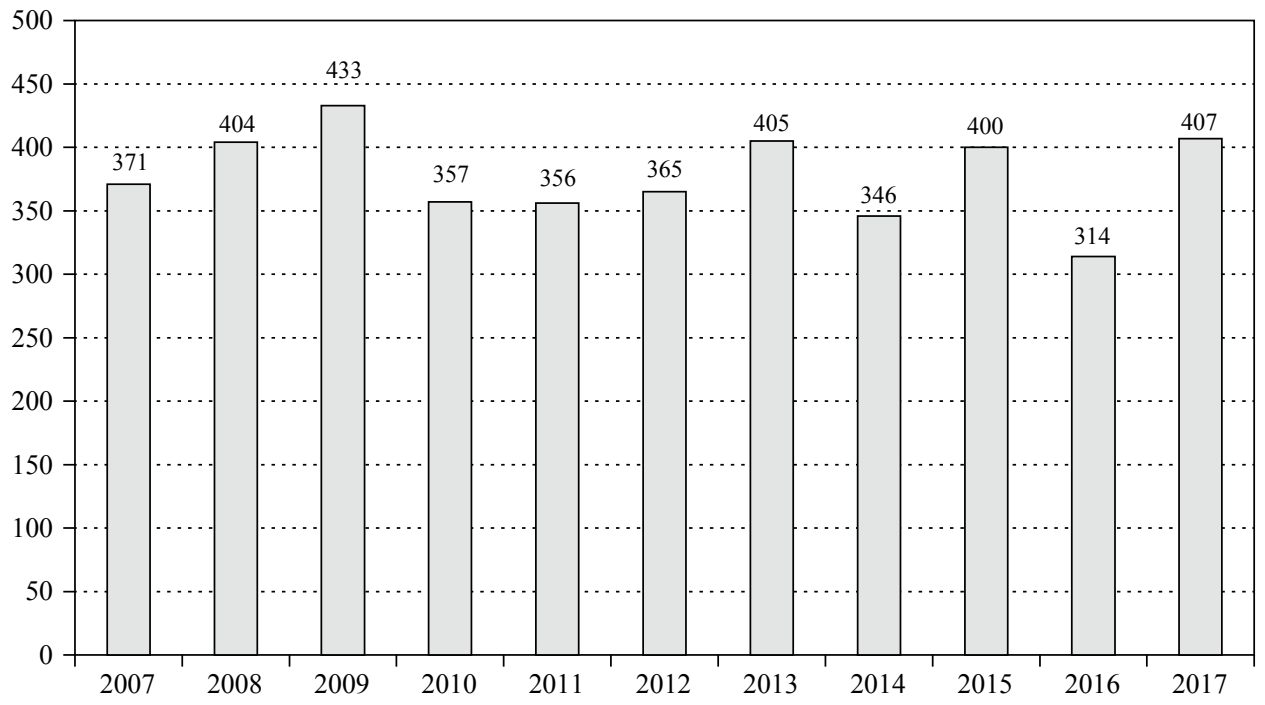

Figure 2. Use of strategic actions of dairies between 2007 and 2017 (absolute values, $n=4,158$ ).

More accurate statements about the adaptation of strategies can be derived by determining the relative importance of individual actions in the total amount of actions performed. Figure 3 shows the development using the example of the years 2007, 2010, and 2014. It becomes clear that in 2014, shortly before the end of the quota, the significance of foreign market entries has doubled compared to 2007. This trend also applies to almost all other strategic actions in foreign countries. The share of investments has tripled since 2007 and accounts for $9 \%$ of the total actions performed in 2014. In the same period the relevance of product policy, product innovation and price policy has declined.

Comparing 2014 with 2016 and 2017 (not reported) it shows that after the end of the quota again more product and brand policy are used. Activities in foreign markets are declining. 


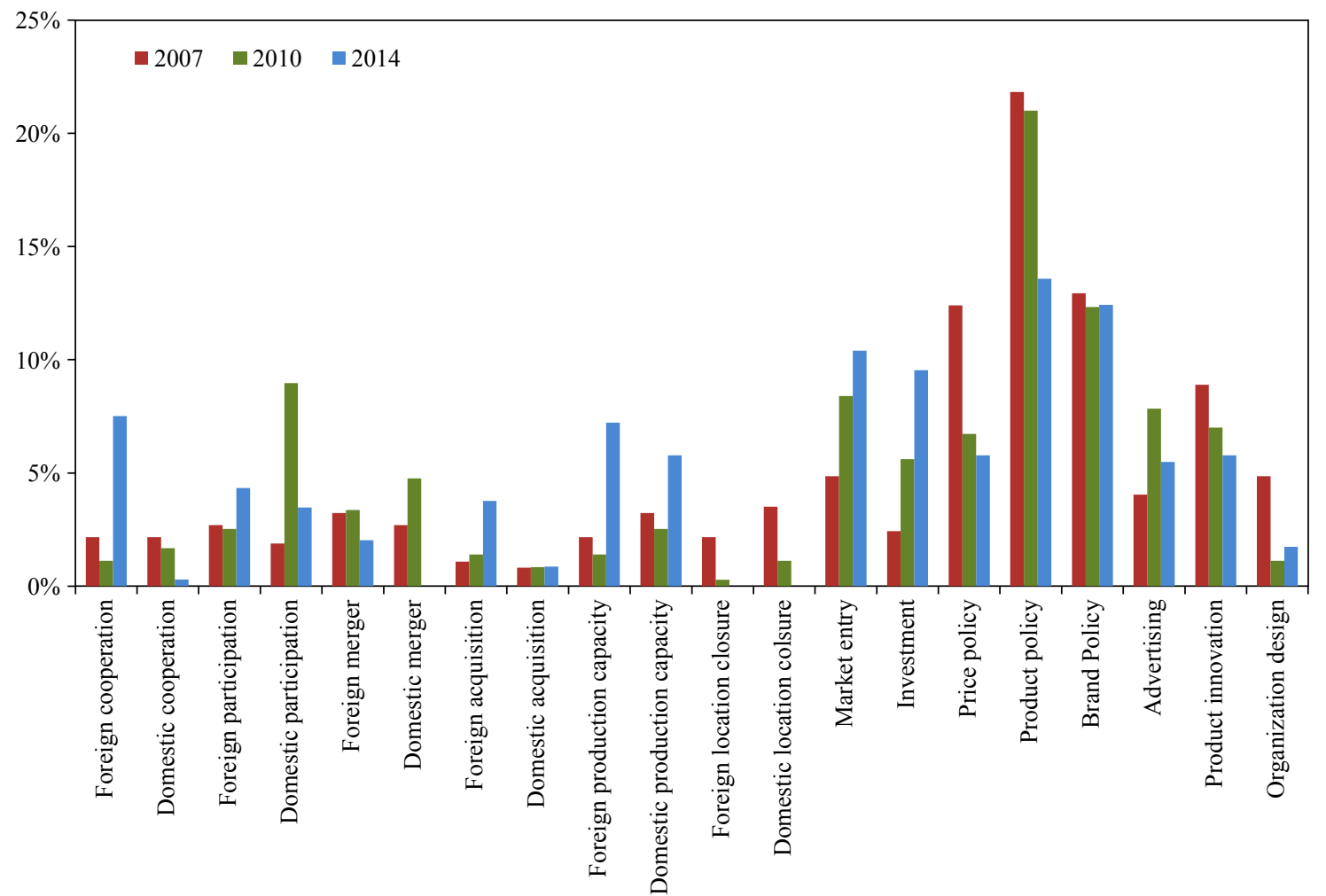

Figure 3. Percentage use of strategic actions by dairies in 2007, 2010 and 2014.

\subsection{Strategic profiles: strategies of selected companies}

One way of evaluating the information on the companies' strategic actions is the formation of strategic profiles. Under strategic profiles we understand the presentation of all strategic actions performed by a company within a given period of time. The evaluation involves creating box plots of all strategic actions. Box plots offer an initial analysis as at first sight the position and the variance of the various actions can be assessed. It can be assessed how often actions have been mentioned in the news and whether companies have adapted their strategies to changing environmental conditions. The spread and the number of outliers (asterisks, circles) show how consistently a strategic action has been applied over the years. Using the example of company 2 a strategic profile is shown in Figure 4.

Company 2 is strongly focused on product policy, brand policy and domestic participation. Further important actions are advertising and product innovation. This profile can now be matched to other profiles, for example with company 3 (Figure 5).

For company 3, the differences in the use of the various actions are not high. Compared to company 2, it is also noticeable that there is a lower span and a higher number of outliers. The most frequent occurrences are product policy, domestic production capacity, and market entry. In 2017, the company appears to be increasingly focused on product policy, brand policy and advertising. The company was much less addressed in the media than company 2. It is possible that fewer strategic actions were performed. Alternatively, the company could communicate less externally. 


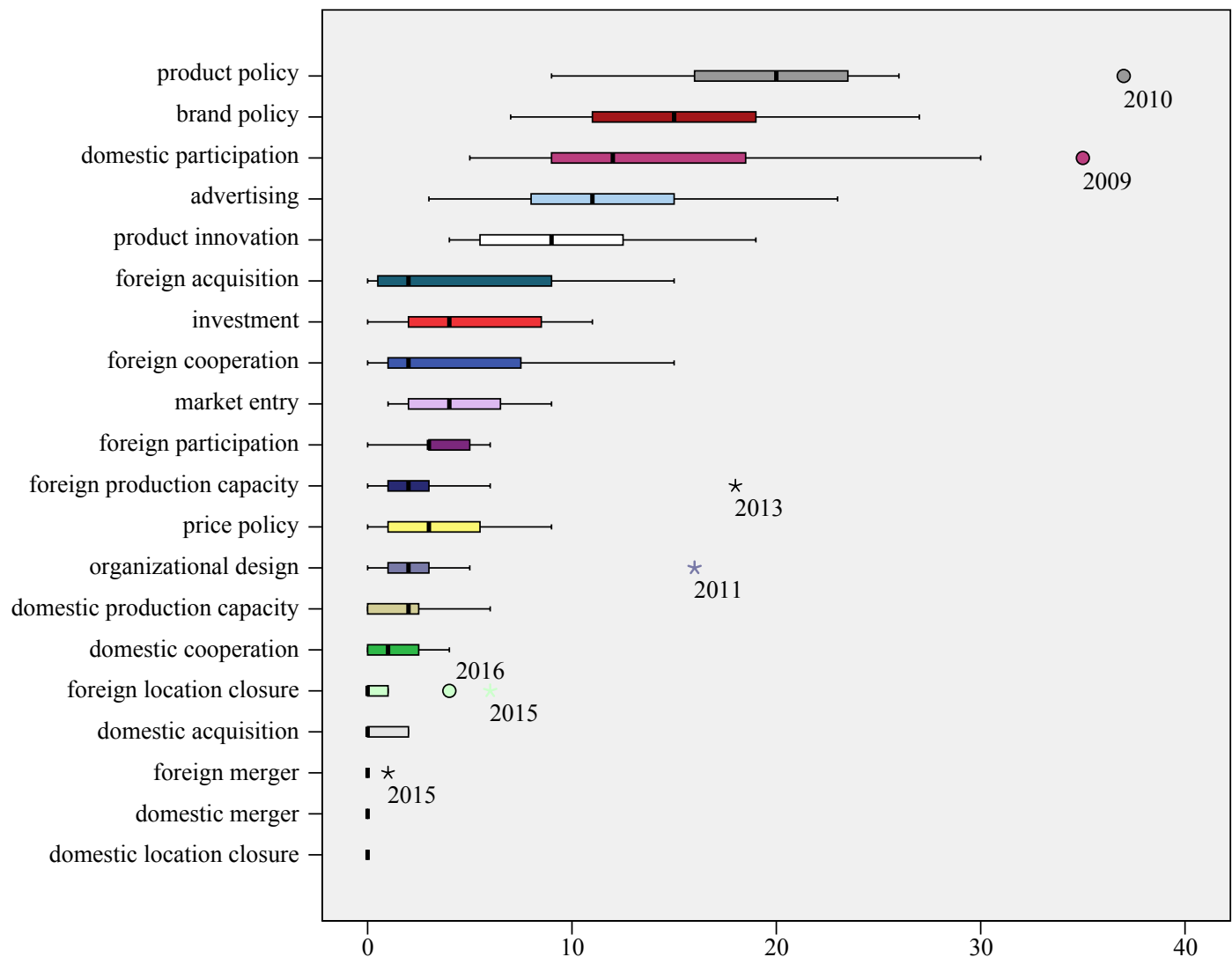

Figure 4. Strategic profile of company 2: box plots for the different actions.

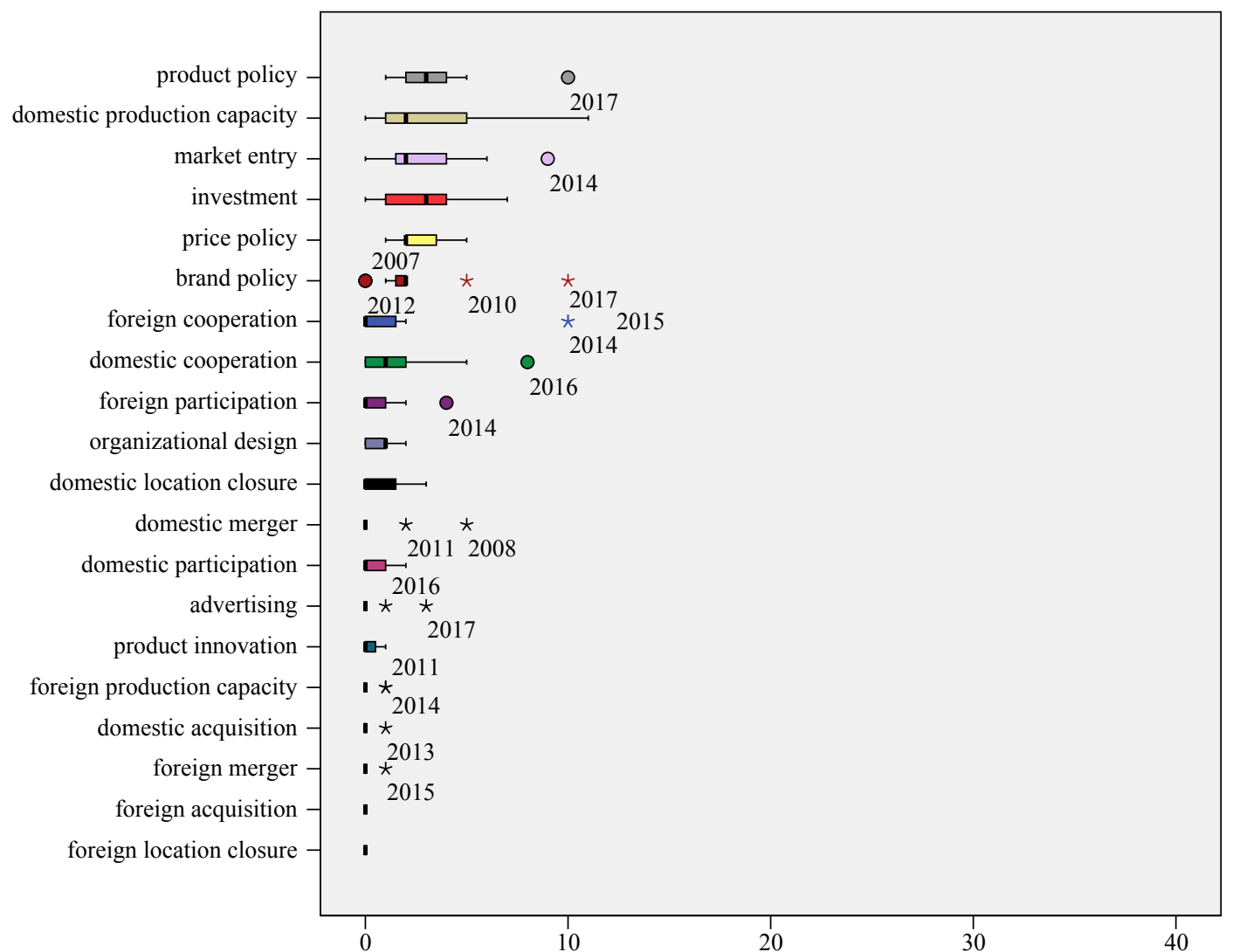

Figure 5. Strategic profile of company 3: box plots for the different actions. 
By looking at the box plots comparisons can be made based on the following questions:

- Which strategic actions were carried out particularly often?

Companies seem to deal differently with environmental developments and seem to pursue different goals with their strategies. Although both companies use product policy most frequently, they differ in their rankings and in the frequency with which other actions are performed. Company 2 focuses primarily on brand policy and domestic participation. Company 3 is expanding its domestic production capacity and entering foreign markets. Company 3 is a cooperative. It is obliged to purchase all the milk of its members. This milk has to be marketed. The strategy is thus also an expression of the use of resources. Company 2 is best known for its brands. These existing resources are used by choosing the actions.

- Were the strategic actions used differently over the observation period or was there a consistent strategy of a company?

Company 2 uses product policy above average every year. Company 3, on the other hand, uses some actions only in a few years. This could be an indication that company 3 has tried to adapt to the changing conditions or that it has not positioned itself clearly. Reasons could also be personnel changes or different views of member groups about the strategic orientation.

\subsection{Strategic groups: similarities and differences in strategies}

Based on the occurrence of similar actions strategic groups can be delineated (Porter, 1980). The assignment to a strategic group can, for example, involve a higher bargaining power (Porter, 1980) and it can be helpful in analyzing industries or policies (Traill, 2000). The knowledge of their own assignment enables companies to recognize their own strategic position and to identify their competitors (Chen, 1996).

For our analysis of strategic groups we used the two-step cluster analysis (IBM, 2012). It is suitable for our type of data and the method provides an automatic determination of the number of clusters. In addition a quality measure is issued for the assessment of the cluster solution (Bacher et al., 2004). It also indicates how important the different variables are for the assignment to the groups. This is a criticism of other procedures (Ketchen and Shook, 1996). The method is based on the assumption that the variables are independent and normally distributed. However, it is robust against deviations from these assumptions (IBM, 2012). Based on our observations so far we chose the variables 'brand policy', 'product policy' and 'foreign market entry' as cluster variables. The cases were clustered with the Bayesian information criterion. The distance measure was log-likelihood. A solution with three clusters was obtained. The Silhouette measure of cohesion and separation points to a good solution. The higher (lower) this value the closer the values are on average to their own (to the nearest other) cluster center. As an alternative specification a factor analysis of all actions was performed. The six identified factors were used for cluster analysis. The resulting two-cluster solution had a lower cluster quality. In Figure 6 the importance of individual variables for the assignment to the clusters is determined.

As can be seen in Figure 6 brand policy is the most important criterion for distinguishing between the three clusters. There seem to be companies that have above-average use of branding and other companies with less than average branding. The cases in our analysis are the respective years for the respective companies (10 companies and 11 years). The cases in cluster 2 show an average of 16.25 times with the strategic action brand policy in the news. The cases in cluster 1 show 1.81 times. Cluster 3 is in the middle. The same applies to the order of product policy: cluster 2 is the most frequently mentioned cluster. For the entry into foreign markets, cluster 3 is the strongest group. On average 7.9 hits are available. This action is the weakest in cluster 1. A discriminant analysis confirms the resulting cluster solution (Wilk's Lambda $=0.073, P=0.00$, Wilk's Lambda $=0.339, P=0.00$ ). 
Input (Predictor) Importance

$\square 1.0 \square 0.8 \square 0.6 \square 0.4 \square 0.2 \square 0.0$

\begin{tabular}{|l|c|c|c|}
\hline Cluster & \multicolumn{1}{|c|}{1} & 2 & 3 \\
\hline Inputs & brand policy & brand policy & brand policy \\
& 1.81 & 16.25 & 3.95 \\
\cline { 2 - 4 } & $\begin{array}{c}\text { product policy } \\
3.43\end{array}$ & $\begin{array}{c}\text { product policy } \\
19.90\end{array}$ & $\begin{array}{c}\text { product policy } \\
5.30\end{array}$ \\
\cline { 2 - 4 } & market entry & market entry & market entry \\
& 0.99 & 5.05 & 7.90 \\
\hline
\end{tabular}

Figure 6. Importance of the input variables for the cluster solution.

In a contingency table, we can analyze the assignment of the company years to the clusters (see supplementary Table S5). It turns out that companies were assigned to the different clusters with different frequency. For example, company 2 is located nine times in cluster 2 . Company 1 , on the other hand, ${ }^{1}$ is allocated cluster 1 in seven years. Companies 4 and 8 are particularly common in cluster 3 (five and four times). It can be stated that the classification into the groups cannot be considered statically. Rather, the group allocation changes over time. A Chi-square test shows that there is a connection between companies and their allocation to a strategic group $\left(\chi^{2}=71.429, P=0.000\right)$.

\subsection{Strategies as patterns}

As described above, companies face a number of challenges with regard to the various stakeholders. The content analysis data allows analyzing patterns of strategies with respect to different challenges. Figure 7 shows what such a pattern may look like with regard to animal welfare. All statements and strategic actions regarding animal welfare were shortened and plotted on a timeline.

The figure shows that Arla had already been dealing with the topic in a public-effective way at an early stage. The early reports from other countries show that the topic was relevant elsewhere in the past. In addition, it can be seen that the initiative in the German market was often taken by food retailers. The top 10 companies DMK and Hochwald are mentioned for the first time in 2017 in connection with animal welfare. Both admit that they have some catching up to do. At the same time a representative of a private dairy company puts forward the thesis that private dairies are pioneers in the field of animal welfare.

\subsection{Influence of strategies on performance}

Another possible use of the data is to link it to performance. We would like to discuss this possibility even if in our case, due to publication obligations, not enough data is available to carry out this analysis. The ten companies were monitored over a period from 2007 to 2017. An observation is available for each year and each type of strategic action. A panel model would therefore be one possible way to further evaluate the data. If we were to have success rates (e.g. profit) from the annual reports we could use these as dependent variables to determine the impact of the strategic actions on the profit ratio. The approach would make it possible to examine the impact of strategies in various business-related questions. One possibility is the investigation of success factors and firm profitability. Other variables could also be added to the panel model, for example, company size, market shares, balance sheet ratios or R\&D expenditures. The Profit Impact of Marketing Strategies (PIMS) framework (Buzzell and Gale, 1987) identifies other important factors that should be integrated into such an analysis.

\footnotetext{
${ }^{1}$ Company 1 is the highest-performing company according to the above mentioned top 10 list.
} 


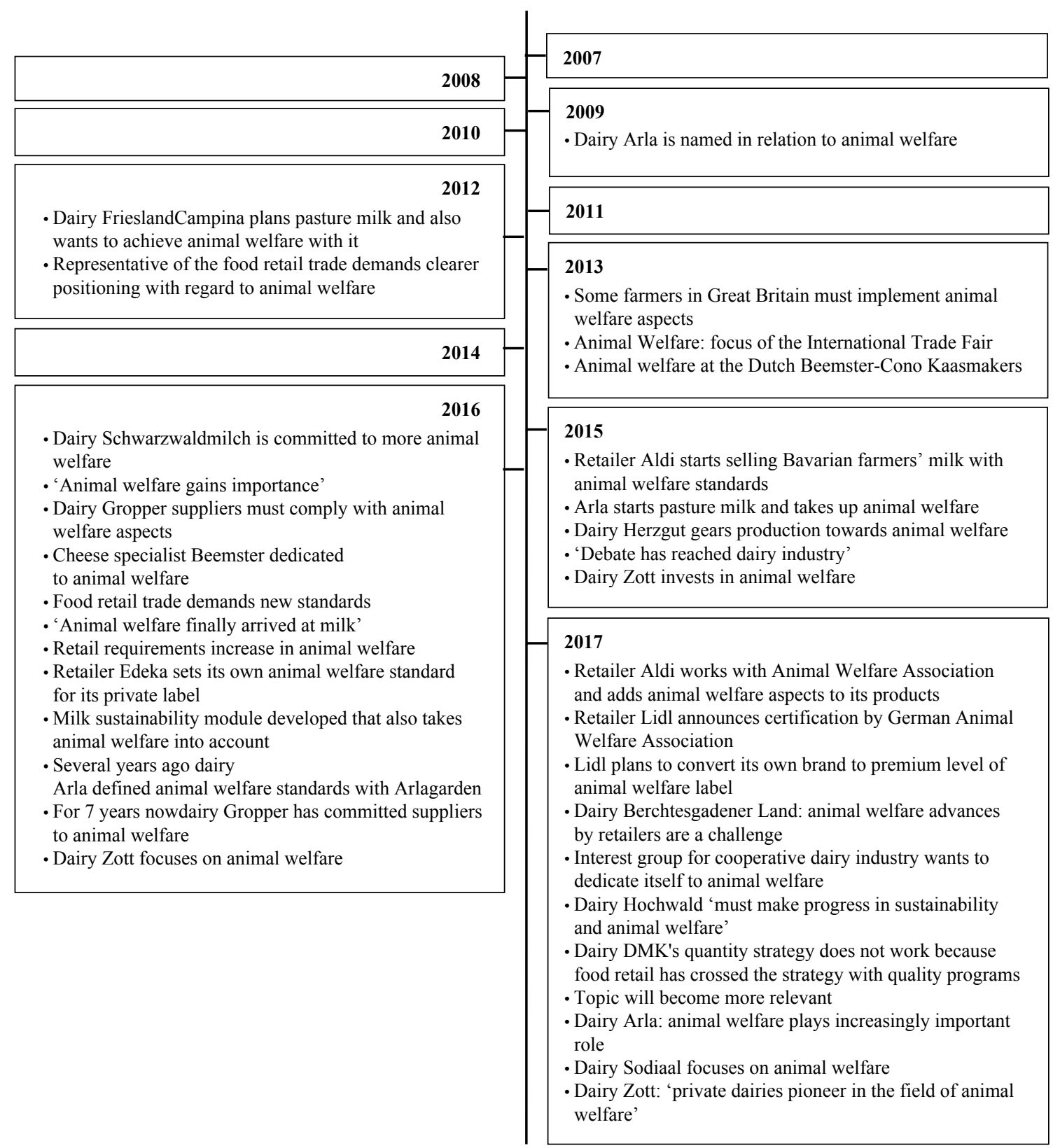

Figure 7. Statements and strategic actions on animal welfare in the dairy industry.

\section{Discussion}

This study proposes the use of content analysis to empirically capture and analyze realized strategies. Content analysis offers advantages over traditional research methods since the results are less affected by response distortions and strategic response behavior. In addition, high case numbers can be collected independent of time and continuously. This allows the dynamics and complexity of realized strategies to be better captured. Previous applications of content analysis in organizational research pursue other goals (competitive dynamics research) and therefore grasp the actions of companies too roughly for a comprehensive analysis of strategies. Consequently, our primary goal was to refine the application of content analysis in the empirical recording of strategies and thus to demonstrate the potential of the method.

For the purpose of our investigation we developed fourteen categories that capture the strategies of companies over a wide range. Based on the resource-based view (Barney, 1991), on Porter's (1980) competitive strategies 
as well as on Ansoff's (1957) product market concept, we identified the following actions: cooperation, participation, merger, acquisition, production capacity, location closure, market entry, investment, price policy, product policy, brand policy, advertising, product innovation and organizational design. For some actions we also differentiated between domestic and foreign actions. We identified 4,158 mentions of strategic actions for the top 10 dairy companies in trade journal articles over a period of 11 years. We showed various possibilities to use these qualitative results quantitatively in strategy research.

First, we analyzed the overall use of strategic actions. From this we derived statements about the priorities in the industry. In our case product policy and brand policy are used most frequently. This reflects developments in the corporate environment and in particular the saturation of the market. However, it should be emphasized that the type of action also determines the frequency of its use. We then showed the use of the actions over time. Before the end of the milk quota market entry into foreign markets was gaining in importance. Shortly after that fewer actions were performed. Other developments could also be responsible for this (e.g. changes in the world market, further regulations). The aggregated representation of the actions can be used to compare different industries and to examine their responses to external shocks. The application of the proposed method in different contexts can form the basis for the comparison of empirical results in strategic management.

In the next step we compiled the strategic actions for individual companies. The analysis of the utilized actions by means of box plots demonstrates the degree of consistency in the use of strategic actions over the years. The resulting individual strategic profiles indicate differences between companies in the use of the actions. While the private company was more focused on brand and product policy the cooperative focused on capacity expansion. This makes sense in connection with the cooperatives' obligation to purchase. This is also the result of the cooperatives' obligation to purchase. An adjustment of the contractual relationship could help to improve volume management and achieve higher milk prices for farmers (Petersen and Hess, 2018). The results can also be used to determine the quality of the strategy according to Hambrick and Fredrickson (2001). The main aspects that can be examined using the results of the content analysis are the fit of the strategy to the environment, the exploitation of core resources, the sustainable differentiation from competitors, as well as the consistency of the strategies. In addition, the results offer the necessary prerequisites for the creation of a sustainable business model (Teece, 2010).

By using a cluster analysis we gained further insights into strategic groups and their stability over time. Three groups can be isolated, which differ in the application of the actions. Here we challenge the existing knowledge about strategic groups since it is usually assumed that the affiliation is stable. Further work is necessary to investigate the stability of the classification and possible reasons for a change.

With the systematic presentation of statements and strategic actions regarding animal welfare in the dairy industry patterns can be made visible. It becomes clear that the trend was initially recognized abroad and was not increasingly reflected in the German media until 2016. It is also interesting to note that the initiative often came from food retailers. In the future managers could observe the market more closely in order to set their own standards. The advantages are lower investment costs and independence from retail standards.

The proposed panel model allows further questions to be addressed, such as the influence of the chosen strategies on the success achieved by the companies. Moreover, the panel model offers the possibility to integrate further variables into the analysis and can thus be applied not only in strategic research but also in success factor research. Examples of such variables are company size, market share or legal form. This can contribute to a better understanding of the determinants of a company's success.

The actions can be changed and complemented depending on the application. Thus, the method can also be used for different countries and industries. As Vracheva et al. (2016) have already emphasized in relation to enterprise strategies, a comparison between countries can be used for a further investigation of contextual and institutional effects on strategies. The method also provides the ability to use large datasets and automatically capture data. Automatic coding makes it possible to quickly evaluate the data records (Short et al., 2018). 
Our research is not without limitations. First, the results are influenced by the definitions and delineation (e.g. foreign and domestic) of the strategic actions. Instead of specifying definitions, an explorative approach would also be possible (Duriau et al., 2007). While some categories may be complementary and may make unambiguous classification difficult - other categories of strategic actions may not be observable at all. This applies, for example, to changes in contracts or organizational structures. Second, we arbitrarily determined a time horizon of one year for comparing the use of strategic actions. A further development of the work could compare the sum of actions for different periods of time and sequences (Kunisch et al., 2017). The available database and the period of time could also be expanded to give more robust results. Moreover, we have not considered the reasons for different strategies. Many variables, such as company size, the variety of products, the composition of the board and legal form, could have an impact on the strategic actions carried out. The actions are thus endogenous. Furthermore, the method also reaches its limits due to the availability of information and the different communication policies of the companies. Also, the authors of the analyzed media articles could distort the contents and lead to a selection bias in favor of larger companies. A combination of our method with additional methods would be best to track down different areas of strategy (e.g. intended vs emergent) and to validate the results (Snow and Hambrick, 1980).

\section{Supplementary material}

Supplementary material can be found online at https://doi.org/10.22434/IFAMR2019.0008.

Table S1. Investigated dairy companies.

Table S2. Codes for our empirical survey.

Table S3. Continued: codes for our empirical survey.

Table S4. Descriptive statistics: strategies of all companies.

Table S5. Company * TwoStep cluster number contingency table.

\section{References}

Ansoff, H. I. 1957. Strategies for diversification. Harvard Business Review 35: 113-124.

Association of the German Dairy Industry. 2017. Top 10 dairy firms in Germany 2016. Available at: https:// milchindustrie.de/wp-content/uploads/2017/10/TOP_Molkereien_DE_2016_Homepage.pdf

Association of the German Dairy Industry. 2018. Annual report 2017/18. Available at: https://milchindustrie. de/wp-content/uploads/2018/09/MIV_Geschaeftbericht_2017-18.pdf

Axelrod, R. 1976. Structure of decision. Princeton University Press, Princeton, NJ, USA.

Bacher, J., K. Wenzig and M. Vogler. 2004. SPSS TwoStep Cluster - a first evaluation. Discussion paper. University of Erlangen Nuremberg. Available at: http://www.ssoar.info/ssoar/handle/document/32715.

Barney, J. 1991. Firm resources and sustained competitive advantage. Journal of Management 17: 99-120.

Berelson, B. 1952. Content analysis in communication research. Free Press, Illinois, IL, USA.

Bergh D.D., B.M. Sharp, H. Aguinis and M. Li. 2017. Is there a credibility crisis in strategic management research? Evidence on the reproducibility of study findings. Strategic Organization 15: 423-436.

Buzzell, R.D. and B.T. Gale. 1987. The PIMS principles: linking strategy to performance. Free Press, New York, NY, USA.

Camerer, C.F. 1991. Does strategy research need game theory? Strategic Management Journal 12: 137-152.

Chandler, A.D. 1962. Strategy and structure: chapters in the history of the industrial enterprise. The MIT Press, Cambridge, MA, USA.

Chen, M.-J., K.G. Smith and C.M. Grimm. 1992. Action characteristics as predictors of competitive responses. Management Science 38: 439-455.

Chen, M.-J. 1996. Competitor analysis and interfirm rivalry: toward a theoretical integration. The Academy of Management Review 21: 100-134.

Dijksterhuis, G. 2016. New product failure: five potential sources discussed. Trends in Food Science and Technology 50: 243-248. 
Durand, R., R.M. Grant and T.L. Madsen. 2017. The expanding domain of strategic management research and the quest for integration. Strategic Management Journal 38: 4-16.

Duriau, V.J., R.K. Reger and M.D. Pfarrer. 2007. A content analysis of the content analysis literature in organization studies. Research themes, data sources, and methodological refinements. Organizational Research Methods 10: 5-34.

Eurostat. 2017. Milk collection (all milks) and dairy products obtained - annual data. Available at: http:// appsso.eurostat.ec.europa.eu/nui/show.do?dataset=apro_mk_pobta\&lang=en.

Eurostat. 2018. Household consumption by purpose. Available at: http://ec.europa.eu/eurostat/statisticsexplained/index.php/Household_consumption_by_purpose.

Ferrier, W.J., K.G. Smith and C.M. Grimm. 1999. The role of competitive action in market share erosion and industry dethronement: a study of industry leaders and challengers. The Academy of Management Journal 42: 372-388.

German Federal Cartel Office. 2009. Milk sector inquiry. Interim report. Available at: https://tinyurl.com/ y5f8429u.

German Federal Cartel Office. 2012. Milk sector inquiry. Available at: https://tinyurl.com/y696bwfq.

German Federal Cartel Office. 2014. Sector inquiry 'buyer power in the food retail sector'. Available at: http://www.bundeskartellamt.de/SharedDocs/Meldung/EN/Pressemitteilungen/2014/24_09_2014_ SU_LEH.html.

German Fe⿳亠丷⿵冂丶 Ministry of Food and Agriculture. 2019. Concentration of supply in chosen food manufacturing industries. Available at: : https://www.bmel-statistik.de/fileadmin/user_upload/monatsberichte/SJT4101800-0000.xlsx.

Graubner, M., I. Koller, K. Salhofer and A. Balmann. 2011. Cooperative versus non-cooperative spatial competition for milk. European Review of Agricultural Economics 38: 99-118.

Hafsi, T. and T. Howard. 2005. The field of strategy: In search of a walking Stick. European Management Journal 23: 507-519.

Hambrick, D. 1980. Operationalizing the concept of business-level strategy in research. Academy of Management Review 5: 567-575.

Hambrick, D.C. and J.W. Fredrickson. 2001. Are you sure you have a strategy? Academy of Management Executive 15: 48-59.

Helbling, M. and A. Tresch. 2011. Measuring party positions and issue salience from media coverage: discussing and cross-validating new indicators. Electoral Studies 30: 174-183.

Hijmans, E. 1996. Review essay. The logic of qualitative media content analysis: a typology. The European Journal of Communication Research 21: 93-108.

Höhler, J. and R. Kühl. 2014. Position and performance of farmer cooperatives in the food supply chain of the EU-27. Annals of Public and Cooperative Economics 85: 579-595.

IBM 2012. Twostep cluster analysis. Available at: https:/www.ibm.com/support/knowledgecenter/en/ SSLVMB_24.0.0/spss/base/idh_twostep_main.html.

Idenburg, P.J. 1993. Four styles of strategy development. Long Range Planning 26: 132-137.

Ketchen, D.J. and C.L. Shook. 1996. The application of cluster analysis in strategic management research: an analysis and critique. Strategic Management Journal 17: 441-485.

Kohlbacher, F. 2006. Theuse of qualitative content analysis in case study research. Forum: Qualitative Social Research 7: 1-30.

Krippendorf, K. 2004. Content analysis: an introduction to its methodology ( $2^{\text {nd }}$ edition). Sage Publications, Thousand Oaks, CA, USA.

Kunisch, S., J. Bartunek, J. Mueller and Q. Huy. 2017. Time in strategic change research. Academy of Management Annals 11: 1005-1064.

Lebensmittel Zeitung 2017. Media information. Available at: http://www.lebensmittelzeitung.net/news/ media/12/LZ-Digital-Media-Kit-2017-117739.pdf.

Markides, C. 2004. What is strategy and how do you know if you have one? Business Strategy Review 15: 5-12.

MaxQDA 2017. MaxQDA. Available at: http://www.maxqda.com/. 
Mehlhose, C., C. Hunecke, A. Spiller and B. Brümmer. 2019. Der Markt für Milch und Milcherzeugnisse im Jahr 2018 (in German). German Journal of Agricultural Economics 68 Supplement: 62-84.

Mintzberg, H. 1978. Patterns in strategy formation. Management Science 24: 934-948.

Osgood, C.E., S. Saporta and J.C. Nunnally. 1956. Evaluative assertion analysis. Litera 3: 47-102.

Petersen, J. and S. Hess. 2018. The future of milk delivery relations from the perspective of German farmers. German Journal of Agricultural Economics 2: 80-94.

Porter, M.E. 1980. Competitive strategy: techniques for analyzing industries and competitors. The Free Press, New York, NY, USA.

Roberts, C.W. 1997. Text analysis for the social sciences: methods for drawing statistical inferences from texts and transcript. Lawrence Erlbaum, Mahwah, NJ, USA.

Ronda-Pupo, G.A. and L.A. Guerras-Martin. 2012. Dynamics of the evolution of the strategy concept: 19622008: a co-word analysis. Strategic Management Journal 33: 162-188.

Sexton, R.-J. 2012. Market power, misconceptions, and modern agricultural markets. American Journal of Agricultural Economics 95: 209-219.

Short, J.C. and T.B. Palmer. 2008. The application of DICTION to content analysis research in strategic management. Organizational Research Methods, 11: 727-752.

Short, J.C., A.F. McKenny and S.W. Reid. 2018. More than words? Computer-aided text analysis in organizational behavior and psychology research. Annual Review of Organizational Psychology and Organizational Behavior 5: 514-535.

Smith, K.G., W.J. Ferrier and H. Ndofor. 2001. Competitive dynamics research: critique and further directions. In Handbook of strategic management, edited by Hitt M., R.E. Freeman and J. Harrison. Blackwell Publishers, London, UK, pp. 315-361.

Smith, K.G., C.M. Grimm, M.J. Gannon and M.-J. Chen. 1991. Organizational information processing, competitive responses, and performance in the U.S. domestic airline industry. Academy of Management Journal 34: 60-85.

Snow, C.C. and D.C. Hambrick. 1980. Measuring organizational strategies: some theoretical and methodological problems. Academy of Management Review 5: 527-538.

Teece, D.J. 2010. Business models, business strategy and innovation. Long Range Planning 43: 172-194.

Traill, B.W. 2000. Strategic groups of EU food manufacturers. Journal of Agricultural Economics 51: 45-60.

Uhlenbruck, K., M. Hughes-Morgan, M.A. Hitt, W. Ferrier, and R. Brymer. 2017. Rivals' reactions to mergers and acquisitions. Strategic Organization 15: 40-66.

Valeeva, N.I., M. Meuwissen, A. Oude Lansink and R. Huirne. 2006. Cost implications of improving food safety in the Dutch dairy chain. European Review of Agricultural Economics 33: 511-541.

Van Atteveldt, W. 2008. Semantic network analysis. Techniques for extracting, representing, and querying media content. BookSurge Publishers, Charleston, SC, USA.

Van der Krogt, D., J. Nilsson and V. Høst. 2007. The impact of cooperatives' risk aversion and equity capital constraints on their inter-firm consolidation and collaboration strategies - with an empirical study of the european dairy industry. Agribusiness 23: 453472.

Voigt, T.A. 2011. Das Datenerhebungsdilemma in der empirischen Strategieforschung. Methodendiskussion und Handlungsempfehlungen am Beispiel der Lebensmittelindustrie (in German). Wiesbaden: VS Verlag für Sozialwissenschaften/Springer Fachmedien Wiesbaden, Wiesbaden, Germany.

Vracheva, V., W.Q. Judge and T. Madden. 2016. Enterprise strategy concept, measurement, and validation: Integrating stakeholder engagement into the firm's strategic architecture. European Management Journal 34: 374-385.

Weber, R. 1990. Basic content analysis ( $2^{\text {nd }}$ edition). Sage Publications, Newbury Park, CA, USA.

Wernerfelt, B. 1984. A resource-based view of the firm. Strategic Management Journal 5: 171-180. 